\title{
Workshop Report: Dissecting the Ethics of Organ Donation: One-Day Intensive
}

\author{
Emna Malas \\ University of Sydney \\ Rosie Duivenbode \\ University of Chicago
}

\begin{abstract}
During the past decade, the number of individuals with organ failure and those in need of organ transplantation has increased, whereas the number of organ donors has remained relatively constant. The resulting gap between "supply and demand" has made organ transplantation an important and widely discussed topic. Compared to the general American population, 95 percent of whom support organ donation, according to survey research only 15-51 percent of Muslim Americans support it. Moreover, as Islamic scholars and jurists continue to discuss its permissibility and associated medical technologies, organ transplantation remains a contentious issue for Muslim patients, chaplains, and physicians.
\end{abstract}

For this reason, on September 10, 2018, the University of Chicago's Initiative on Islam and Medicine, along with support from the Chicago Muslim Medical Alliance, held a one-day intensive workshop on the "Ethics of Organ Donation." The program featured a line-up of national and international scholars who addressed the biomedical, philosophical, and ethico-legal underpinnings of organ transplantation from the perspective of both Islamic and Muslim bioethics, to borrow Professor Aasim Padela's key terminology. ${ }^{1}$

The event kicked off with a networking dinner for attendees and presenters. Breaking bread together over a game of trivia was both a great ice breaker and an ingenious way to introduce the workshop's topics, which ranged from determining the percentage of American Muslim physicians who are registered organ donors (answer: 30 percent), to answering who is generally considered the father of the higher objectives of the Sharia (answer: Imam al-Shâțibī [d. 1388]). I recall this last question in particular, as it was the only one that I answered correctly. The highlight of the evening was being able to pick the minds of some of the brilliant men and women in the field, such as Profs. Abdulaziz Sachedina, Peter Pormann, Ayman Shabana, and Dr. Mehrunisha Suleman.

\footnotetext{
${ }^{1}$ Dr. Padela defines Islamic bioethics as a discourse that uses the Islamic tradition to address moral questions and ethical issues arising out of the biomedical sciences and allied health practices. Muslim bioethics, on the other hand, refers to the sociological study of how Muslims respond to bioethical challenges with Islam as one input.
} 
The workshop was attended by a wide array of physicians, chaplains, nurses, and other allied healthcare professionals, as well as imams and religious scholars. The intensive one-day program consisted of three main components: an introduction to Islamic bioethics, an evaluation of organ donation's biomedical aspects, and a comprehensive review of the religious perspectives on this procedure.

The day began with Dr. Padela's introduction to Islamic bioethics. After highlighting the distinction between Islamic, Muslim, and applied Islamic bioethics, ${ }^{2}$ he identified the discourse's key stakeholders and the material outputs that we can expect to find. His talk was followed by two very engaging presentations on the biomedical aspects of living organ donation. Dr. Milda Saunders, a living donor advocate physician at the University of Chicago's transplant center, explored kidney disease and the need for living donors within the American context, as well as the inherent societal benefits and individual medical risks of living kidney donation. Next, Dr. Talia Baker, a transplant surgeon at the University of Chicago, addressed the ethical conflicts in living donor liver transplantation, such as that between the donor's autonomy (and her right to donate an organ freely) and the transplant physician's adherence to the Hippocratic non-maleficence principle (while being in a position of possibly harming a donor who may not stand to benefit).

Dr. Padela then took to the floor again and presented an Islamic perspective on the ethico-legal issues relating to organ donation. He discussed the various fatwas on this procedure, the underlying constructs, and the legal continuum upon which they exist. Along this continuum he identified three positions: (1) categorical impermissibility, due to violations of human dignity (hurma and karāma); (2) impermissibility, but permitted on a conditional basis when there is a dire need (darüra); and (3) permissible or encouraged, based on the notion of public interest (mașlaha). The conditions attached to its permissibility (e.g., minimizing the violation of hurma, obtaining the donor's consent, and the necessity and probability of success of the organ's transplantation) were also explored.

After a lunch break, anthropologist Dr. Elham Mireshghi and two panel discussions laid out several lively and controversial Muslim debates on organ donation. She discussed the unique situation of paid living kidney donation in Iran by introducing the socio-political context and Shi'a jurisprudential considerations that enabled the development and continuation of one of the world's only long-standing programs for paid kidney giving. The following panels on organ donation and brain death, which featured Shaykh Amin Kholwadia (the Darul Qasim Institute), Sh. Zulfiqar Ali (the Fiqh Council of North America), and Dr. Rafaqat Rashid (Al-Balagh Academy), explored central theological and juridical concepts relating to the

\footnotetext{
2 Applied Islamic bioethics bridges the aforementioned Islamic and Muslim bioethics methodologically by examining how the material of Islamic bioethics is understood and applied by consumers, as well as the transition of biomedical concepts into the edifice of Islamic law.
} 
permissibility of organ donation and defining death. Their detailed overview of the argumentation behind the different juridical positions gave participants the rare opportunity to interact with reputable scholars and observe areas of agreement and disagreement among them.

Centering the panels on the controversies, concepts, and questions surrounding these topics aroused passionate debates from the panel members. I think it is safe to say that although each party put forward many a convincing argument, numerous questions remain as to how Islam regards organ donation and defines death.

This event proved to be valuable for chaplains, imams, physicians, and many other professionals. Its interdisciplinary nature provided both breadth and depth and inspired many stimulating discussions. We hope to see many of you (again) during October 20-22, 2019, when the Initiative on Islam and Medicine (II\&M) will host "Advancing Muslim American Health Priorities (A-MAP): Exploring the Religious Dimensions of Mental, Reproductive and Sexual Health." For more information on this event, visit https://voices.uchicago.edu/islamandmedicine/amap/. 